\title{
Semen quality and reproductive performance of boars kept in pens containing conventional coffee husk as a floor covering
}

\author{
Mariele Cristina Teles¹, Bárbara Azevedo Pereira1', Luiz Gustavo Pessoa Rocha1', Carla Oliveira \\ Resende $^{1}$, Valéria Vânia Rodrigues ${ }^{2}$, Luciano José Pereira ${ }^{3}$, Joan Enric Rodríguez-Gil', \\ Márcio Gilberto Zangeronimo ${ }^{1}$
}

\author{
${ }^{1}$ Universidade Federal de Lavras, Departamento de Medicina Veteerinária, Lavras, MG, Brazil. \\ 2 Universidade José do Rosário Vellano, Departamento de Ciências Agrárias, Alfenas, MG, Brazil. \\ ${ }^{3}$ Universidade Federal de Lavras, Departamento de Ciências da Saúde, Lavras, MG, Brazil. \\ ${ }^{4}$ Autonomous University of Barcelona, Department of Animal Medicine and Surgery, Bellaterra (Cerdanyola del Vallès), Spain.
}

\begin{abstract}
The objective of this study was to evaluate the putative effects of the use of coffee husk as floor covering on boar semen quality. Sixteen boars were divided into two groups. The first group was held in a conventional system with a compact floor. The second group was kept on a compact floor covered with coffee pods. The experimental period was 60 days. Levels of caffeine and chlorogenic acid in the insemination doses (ID) before and after $96 \mathrm{~h}$ of storage at $15{ }^{\circ} \mathrm{C}$ and the reproductive performance (litter size and rate of return to estrus) of these doses after their utilization in a standard artificial insemination protocol were evaluated. The ID from the animals kept in pens containing the coffee pods contained $25.4 \pm 8.7 \mu \mathrm{g} / \mathrm{mL}$ of caffeine, whereas no significant amounts of chlorogenic acid were detected. Semen from boars housed with coffee husk showed a significant increase in malondialdehyde levels, which indicates a significant increase in cell membrane peroxidation, after $96 \mathrm{~h}$ of storage. There were no significant differences in the other evaluated semen quality parameters when analyzed among groups. Likewise, there was no significant influence of coffee hulls on either the rate of return to estrus or the litter size of inseminated females. The use of coffee husks as floor covering worsens the quality of fresh semen and that of insemination doses stored for $96 \mathrm{~h}$ but not the quality of semen immediately diluted; therefore, coffee husks may be used only on farms that use semen immediately processed after collection without affecting the reproductive parameters of breeding stock.
\end{abstract}

Key Words: antioxidant, by-product, caffeine, pig, sperm

\section{Introduction}

In recent decades, there has been a considerable increase in the concern for animal welfare, especially in intensive production systems such as swine. In the current intensive pig production system, boars are normally kept in enclosed bays. This type of management can have a direct influence on the animal welfare (Lovedahl et al., 2005) and semen quality of boars (Gollenberg et al., 2010).

In artificial insemination (AI) in swine, cold-diluted semen is usually used until $72 \mathrm{~h}$ of storage (Johnson et al., 2000). After that time, there is a considerable reduction in quality, mainly due to a reactive oxygen species-induced (ROS-induced) overall cell membrane alteration (Ball et al., 2001; Breininger et al., 2005). Because of this, different

Received December 8, 2015 and accepted May 3, 2016.

Corresponding author: zangeronimo@dmv.ufla.br

http://dx.doi.org/10.1590/S1806-92902016000700002

Copyright (C) 2016 Sociedade Brasileira de Zootecnia. This is an Open Access article distributed under the terms of the Creative Commons Attribution License (http://creativecommons.org/licenses/by/4.0/), which permits unrestricted use, distribution, and reproduction in any medium, provided the original work is properly cited. metabolite substances have frequently been added to semen extenders in order to counteract the deleterious effects caused by inappropriate functioning of the endogenous boar sperm metabolism (Mendez et al., 2013).

Coffee husk is a by-product originating from coffee that is often used as organic fertilizer (Pandey et al., 2000), animal feed (Brand et al., 2001), and heat source. During the past several years, some compounds in coffee such as caffeine have attracted interest due to their pharmacological properties. Caffeine is present at $1.3 \%(\mathrm{w}: \mathrm{w})$ of dry matter in natural coffee pods (Yoshida, 2005) and has a stimulating effect on overall sperm metabolism (Louglin and Agarwal, 1992; Chauhan et al., 1998), increasing the ROS during the storage time.

Another important class of compounds present in coffee grains are chlorogenic acids. Chlorogenic acids are present at $0.6 \%(\mathrm{w}: \mathrm{w})$ of dry matter in mature coffee grains (Sanchez-González et al., 2005). These compounds form part of a family of substances with antioxidant properties that are able to neutralize free radicals such as ROS that are formed within cells (Lekse et al., 2001; Ghiuru et al., 2010). Thus, both caffeine and chlorogenic 
acids can generate profound modifications in boar sperm metabolism and hence, in their fertilizing ability. This is an important consideration because coffee husks are utilized as floor covering for boars in geographical areas of coffee cultivation. Therefore, the main aim of this study was to evaluate the putative influence of coffee husk as floor covering on the semen quality and in vivo reproductive performance of boars used for AI.

\section{Material and Methods}

The experiment was conducted between September and November 2013 in the municipality of Oliveira, Minas Gerais, Brazil. All procedures involved in this study were approved by the ethics committee on animal use of Universidade Federal de Lavras, under case no. 008/14. Sixteen breeding pigs of commercial strains (Agroceres, $\mathrm{DB}$, and Genetiporc) of reproductive age between 9 and 30 months, which were trained and adapted to the collection of semen with proven fertility, were used. Animals were housed in individual pens $2.75 \mathrm{~m}$ long, $2.10 \mathrm{~m}$ wide, and $1.30 \mathrm{~m}$ high, enclosed with railings. Boars received $3.0 \mathrm{~kg}$ of feed daily for this specific category, divided into two portions given at 08.00 and $14.00 \mathrm{~h}$. Water was provided ad libitum. The pen was cleaned daily for the removal of excreta and wet material.

Animals utilized in the study were divided into two groups. The first group (control) was kept in a conventional system with a compact floor. The second group (coffee group) was kept in a system with a compact floor covered with coffee husk to a thickness of approximately 3.0 to $4.0 \mathrm{~cm}$. Coffee husk coverage was replaced either every four days or when the humidity was considered excessive. The experimental design was completely randomized, with two treatments and eight replicates of one experimental plot represented by two evaluations of each animal. The experimental period was 60 days.

Before the start of the experiment, the semen quality of all of boars utilized was recorded and used as the initial semen quality values in the experimental design. Afterwards, semen from all of the animals was collected once weekly by the gloved hand method with the aid of a fixed dummy in a specially designed collection room. Semen collection was performed in all cases at approximately $9.00 \mathrm{~h}$. Three or four animals were collected daily and the interval between semen collections from each animal was one week. The obtained ejaculates were collected into a graduated jar with a capacity of $500 \mathrm{~mL}$, heated to $37{ }^{\circ} \mathrm{C}$ and protected by an isothermal container. Before collection, the foreskin was cleaned by applying manual pressure to the preputial opening and cleaning the area with paper towels. During collection, the gelatinous fraction of the ejaculate was separated through a matched filter on the collection bottle. Only the rich fraction of the ejaculate was used. After collection, ejaculates were sent to the reproduction laboratory of the farm, where the initial assessments of motility, sperm concentration, and intensity of movements were performed. Prior to arrival of the ejaculate at the laboratory, the diluent Beltsville Thawing Solution (BTS $^{\circledR}$; Minitüb ${ }^{\circledR}$, Minitub GmbH, Tiefenbach, Germany) was prepared according to the recommendations of the manufacturer and maintained at a temperature of $35{ }^{\circ} \mathrm{C}$ in a water bath. After the determination of concentration from the Neubauer chamber, the ejaculate was diluted in the previously warmed $\mathrm{BTS}^{\circledR}$ to a final concentration of $3 \times 10^{9} \mathrm{sperm} / \mathrm{mL}$. Afterwards, the diluted ejaculate was divided into the appropriate number of $100 \mathrm{~mL} \mathrm{AI} \mathrm{doses,}$ which were then kept at room temperature and protected from light for $90 \mathrm{~min}$ before being used for artificial insemination at the farm. All of the material that was used in the seminal assessment and that entered into contact with the semen was warmed to $37{ }^{\circ} \mathrm{C}$ in an oven, in a water bath, or on a hot plate. Semen AI doses collected at the start of the experiment and after 60 days were sent on the same day to the laboratory for evaluation and subsequent storage. Finally, the rate of return to estrus and the litter size were evaluated from AI carried out by AI doses obtained from animals after 60 days from the start of the experimental procedure and immediately processed after collection.

Semen quality was evaluated immediately after the arrival of the appropriate AI doses at the laboratory and after $96 \mathrm{~h}$ of storage at $15{ }^{\circ} \mathrm{C}$. In each evaluation, an aliquot of $10 \mathrm{~mL}$ of the insemination dose was incubated in a water bath at $35{ }^{\circ} \mathrm{C}$. Sperm motility, viability, and acrosome integrity were measured after $5 \mathrm{~min}, 2 \mathrm{~h}$, and $4 \mathrm{~h}$ of incubation. Morphological abnormalities were analyzed only after $5 \mathrm{~min}$ of incubation. Furthermore, samples of $1.0 \mathrm{~mL}$ were also collected after $2 \mathrm{~h}$ of incubation. These samples were immediately centrifuged at $3360 \mathrm{~g}$ for $10 \mathrm{~min}$, and the obtained supernatant was immediately frozen and stored at $-80{ }^{\circ} \mathrm{C}$ until biochemical analysis.

Motility was evaluated through direct visual estimation. For this purpose, three subsamples of $10 \mu \mathrm{L}$ for each sample were placed on warm glass slides $\left(37^{\circ} \mathrm{C}\right)$. Subsamples were covered with $24 \times 24 \mathrm{~mm}$ cover slips and motility was examined under a phase contrast microscope $(100 \mathrm{x})$. A total of 10 microscopic fields were assessed in each subsample to determine the percentage of spermatozoa showing rapid motility and the intensity of movement. Spermatic motility 
was expressed as a percentage of mobile cells, and the intensity of movements was classified on a $0-5$ scale with 0 being low intensity and 5 , maximum intensity.

Sperm viability was determined by using the Eosinnigrosin staining method (Blom, 1950; Bamba, 1988). The percentage of acrosome integrity was evaluated through the POPE-Fast Green/Rose Bengal staining technique (Pope, 1991). Percentages of morphological abnormalities were evaluated without staining and through evaluation in a phase contrast microscope at $1000 \mathrm{x}$ magnification. For this purpose, $300-\mu \mathrm{L}$ aliquots of semen samples were mixed with the same volume of a $3 \%$ formal-citrate solution to fix sperm cells. Finally, the hypo-osmotic swelling test (HOST) was performed following Pérez-Llano et al. (2001). The proportion of cells with a curled tail in both iso-osomotic and hypo-osmotic solutions was evaluated by using a phase contrast microscope at $1000 \mathrm{x}$ magnification. The same three operators evaluated all samples and a consistent sample handling protocol was used throughout the study. Differences greater than $10 \%$ from the mean were considered outliers. In this case, new evaluations were conducted.

At the beginning of the experiment, a $1 \mathrm{~mL}$ sample of each ejaculate was taken prior to dilution in commercial extender. These aliquots were immediately centrifuged at $3360 \mathrm{~g}$ for $10 \mathrm{~min}$ at $37^{\circ} \mathrm{C}$. The obtained supernatants corresponding to the seminal plasma were then immediately frozen at $-80{ }^{\circ} \mathrm{C}$ until their utilization for determining both caffeine and chlorogenic acid levels and lipid peroxidation rates.

Both caffeine and chlorogenic acid were quantified following the methodology described by Azevedo et al. (2008). In the case of caffeine determination in husks, after the extraction of compounds from coffee pods, samples were filtered through a $0.20 \mu \mathrm{m}$-pore membrane and injected into an Ultra Efficiency Liquid Chromatography column (UPLC, LC-2010HT, Shimadzu, São Paulo, Brazil). For the chromatographic analysis, a pre-column and $\mathrm{C}_{18}$ reverse-phase column Shim-pack (Shimadzu, Kyoto - Japan) were used. The isocratic elution was made using methanol:acetic acid:pure water $18.2 \mathrm{M} \Omega$ (25:0.5:74.5, $\mathrm{v}: \mathrm{v}: \mathrm{v})$ as the mobile phase at a flow rate of $1.0 \mathrm{~mL} \mathrm{~min}^{-1}$ at $30{ }^{\circ} \mathrm{C}$. Concentrations of both caffeine and chlorogenic acid were calculated by comparing the peak area of the sample with the peak area of the standard.

In the case of determination of caffeine and chlorogenic acid in seminal plasma, samples were thawed at $-20{ }^{\circ} \mathrm{C}$. Immediately afterwards, samples were filtered through a $0.20 \mu \mathrm{m}$-pore membrane and injected into an Ultra Efficiency Liquid Chromatography column (UPLC, LC2010HT, Shimadzu, São Paulo, Brazil). The subsequent chromatographic analysis was performed by using the same methodology as described above.

Lipid peroxidation of these samples was determined by measuring the concentration of malondialdehyde (MDA) using the QuantiChrom ${ }^{\mathrm{TM}}$ TBARS Assay Kit (DTBA - 100 - Bioassay Systems, Hayward, USA). Samples were then treated according to the instructions of the manufacturer.

The data were subjected to normality of residuals (Shapiro-Wilk test) and homogeneity of variance (Levene test). In the case of no significance, data were subjected to analysis of covariance for paired data, with the baseline characteristics of the semen used as a covariate. In the case of nonparametric data (sperm motility and intensity of sperm motility), means were compared using the Kruskal-Wallis test. For the percentage of return to estrus, the binomial regression model was used, and analysis of covariance was utilized to assess the total born piglets, taking birth order as a covariate. All statistical analyses were performed using Statistical Program Action 2.4, with $\alpha=0.05$.

\section{Results}

Results in all cases are expressed as means \pm standard deviation. Concentrations of caffeine and chlorogenic acid in the coffee husk used during the experiment were $54.0 \pm 11.5 \mathrm{mg} / \mathrm{g}$ dry matter (DM) (caffeine) and $45.4 \pm 6.9 \mathrm{mg} / \mathrm{g}$ DM (chlorogenic acid). Semen samples from animals of the coffee group contained $25.5 \pm 8.7 \mu \mathrm{g} / \mathrm{mL}$ caffeine. On the contrary, no detectable amounts of chlorogenic acid were detected. Neither substance was found in the insemination doses of boars from control group.

The presence of coffee husk did not significantly influence either the volume of ejaculates or the semen concentration, but decreased $(\mathrm{P}<0.01)$ the sperm motility of fresh semen. However, diluted semen from animals in the coffee group did not show significant changes in overall sperm motility characteristics when compared with control group, either immediately after dilution or after $96 \mathrm{~h}$ of storage (Table 1). Thus, the sperm motility of samples from boars in the coffee group stored immediately after the dilution and incubated for $4 \mathrm{~h}$ at $35^{\circ} \mathrm{C}$ was not significantly lower than that of the control group $(59.2 \pm 12.4 \%$ vs. $35.7 \pm 27.6 \%$ in control group; Table 1). A similar lack of significant effects linked to the presence of coffee husk was observed in all of the other semen quality parameters analyzed. Hence, there was no significant difference between control group and coffee group for percentage of viability, abnormalities, acrosome integrity, and HOST at any of the time points analyzed (Table 1). However, semen samples from the coffee group showed a significant $(\mathrm{P}<0.01)$ increase in the 
MDA content, but only after $96 \mathrm{~h}$ of storage $(17.1 \pm 3.11 \mu \mathrm{M}$ vs. $13.7 \pm 3.2 \mu \mathrm{M}$ in control group; Table 1). Nonetheless, this increase had no significant effect on the overall quality of semen after storage.

Regarding in vivo reproductive parameters, there were no significant differences in either the rate of return to estrus or the litter size between control group and coffee group. Thus, as shown in Table 2, the percentage of return to estrus after AI was 3.6 in coffee group vs. 1.5\% in control group, whereas the total number of newborn piglets was $15.6 \pm 3.7$ in coffee group vs. $16.4 \pm 3.3$ in control group.

\section{Discussion}

The results presented in this study clearly suggest that the utilization of coffee husk as bedding does not have any deleterious effects on either overall quality or in vivo fertilizing ability of boar semen when animals are kept under these conditions. This lack of any apparent effect on boar semen quality is obvious despite the presence of caffeine in the semen. This presence indicates that boars are actually interacting with the substrate, probably by ingesting the material placed on the floor. In any case, although boars are able to ingest significant amounts of caffeine, this amount is not enough to influence the quality of the ejaculate for artificial insemination. This is important because caffeine can act on semen quality through separate mechanisms, such as metabolic stimulation (Louglin and Agarwal, 1992; Chauhan et al., 1998), sperm motility activation (Yamaguchi et al., 2013), and ROS-generating induction during the storage of AI doses (Chatterjee and Gagnon, 2001). Caffeine is also able to inactivate

Table 1 - Semen quality parameters of insemination doses of boars kept in pens with or without coffee husk as floor covering for 60 days $(\mathrm{n}=8)$

\begin{tabular}{|c|c|c|c|}
\hline Variable & Coffee group & Control group & P-value \\
\hline \multicolumn{4}{|c|}{ Semen quality parameters after collection } \\
\hline Volume (mL) & $298.3 \pm 31.8 \mathrm{a}$ & $288.0 \pm 44.5 \mathrm{a}$ & 0.64 \\
\hline Sperm concentration $\left(10^{6} \mathrm{sperm} / \mathrm{mL}\right)$ & $296.0 \pm 29.7 \mathrm{a}$ & $307.2 \pm 33.4 \mathrm{a}$ & 0.54 \\
\hline Sperm motility $(\%)$ & $85.0 \pm 3.0 \mathrm{a}$ & $90.0 \pm 3.0 \mathrm{~b}$ & $<0.01$ \\
\hline \multicolumn{4}{|c|}{ Semen quality parameters after dilution } \\
\hline Caffeine concentration $(\mu \mathrm{g} / \mathrm{mL})$ & $25.5 \pm 8.7$ & $0.0 \pm 0.0$ & - \\
\hline Chlorogenic acid concentration $(\mu \mathrm{g} / \mathrm{mL})$ & $0.0 \pm 0.0$ & $0.0 \pm 0.0$ & - \\
\hline Malondialdehyde content $(\mu \mathrm{M})$ & $12.3 \pm 5.2 \mathrm{a}$ & $11.1 \pm 1.6 \mathrm{a}$ & 0.54 \\
\hline Total morphological abnormalities (\%) & $4.3 \pm 3.3 \mathrm{a}$ & $4.1 \pm 1.9 \mathrm{a}$ & 0.26 \\
\hline Viability (\%) & $86.9 \pm 9.3 \mathrm{a}$ & $89.6 \pm 6.0 \mathrm{a}$ & 0.28 \\
\hline Acrosome integrity $(\%)$ & $95.6 \pm 4.5 \mathrm{a}$ & $95.0 \pm 3.3 \mathrm{a}$ & 0.21 \\
\hline Hypo-osmotic test (\%) & $76.0 \pm 6.5 \mathrm{a}$ & $76.1 \pm 4.7 \mathrm{a}$ & 0.96 \\
\hline \multicolumn{4}{|l|}{ Sperm motility at $35^{\circ} \mathrm{C}(\%)$} \\
\hline After 5 min of incubation & $73.6 \pm 8.0 \mathrm{Aa}$ & $75.7 \pm 7.3 \mathrm{Aa}$ & $<0.01$ \\
\hline After $2 \mathrm{~h}$ of incubation & $63.6 \pm 12.8 \mathrm{Ba}$ & $63.3 \pm 14.9 \mathrm{Ba}$ & \\
\hline After $4 \mathrm{~h}$ of incubation & $59.2 \pm 12.4 \mathrm{Ba}$ & $35.7 \pm 27.6 \mathrm{Ba}$ & \\
\hline \multicolumn{4}{|c|}{ Intensity of sperm motility at $35^{\circ} \mathrm{C}$ (arbitrary units) } \\
\hline After 5 min of incubation & $2.9 \pm 0.4 \mathrm{a}$ & $3.0 \pm 0.6 \mathrm{a}$ & 0.18 \\
\hline After $2 \mathrm{~h}$ of incubation & $2.7 \pm 0.5 \mathrm{a}$ & $2.6 \pm 0.5 \mathrm{a}$ & \\
\hline After $4 \mathrm{~h}$ of incubation & $2.6 \pm 0.5 \mathrm{a}$ & $2.3 \pm 0.8 \mathrm{a}$ & \\
\hline \multicolumn{4}{|c|}{ Semen quality parameters after $96 \mathrm{~h}$ of storage } \\
\hline Malondialdehyde content $(\mu \mathrm{M})$ & $17.1 \pm 3.1 \mathrm{a}$ & $13.7 \pm 3.2 b$ & $<0.01$ \\
\hline Total morphological abnormalities (\%) & $4.7 \pm 2.7 \mathrm{a}$ & $6.9 \pm 3.8 \mathrm{a}$ & 0.13 \\
\hline Viability $(\%)$ & $79.3 \pm 19.1 \mathrm{a}$ & $85.4 \pm 8.4 \mathrm{a}$ & 0.08 \\
\hline Acrosome integrity (\%) & $94.0 \pm 3.1 \mathrm{a}$ & $94.1 \pm 3.3 \mathrm{a}$ & 0.33 \\
\hline Hypo-osmotic test (\%) & $74.6 \pm 11.3 \mathrm{a}$ & $69.3 \pm 12.9 \mathrm{a}$ & 0.15 \\
\hline \multicolumn{4}{|l|}{ Sperm motility at $35^{\circ} \mathrm{C}(\%)$} \\
\hline After 5 min of incubation & $7.5 \pm 10.7 \mathrm{Aa}^{*}$ & $8.7 \pm 12.6 \mathrm{Aa}^{*}$ & $<0.01$ \\
\hline After $2 \mathrm{~h}$ of incubation & $0.7 \pm 1.9 \mathrm{Ba}^{*}$ & $2.1 \pm 3.9 \mathrm{Ba}^{*}$ & \\
\hline After $4 \mathrm{~h}$ of incubation & $0.0 \pm 0.0 \mathrm{Ba}^{*}$ & $0.7 \pm 1.9 \mathrm{Ba}^{*}$ & \\
\hline \multicolumn{4}{|c|}{ Intensity of sperm motility at $35^{\circ} \mathrm{C}$ (arbitrary units) } \\
\hline After 5 min of incubation & $1.7 \pm 1.6 \mathrm{a}$ & $2.1 \pm 1.5 \mathrm{a}$ & 0.11 \\
\hline After $2 \mathrm{~h}$ of incubation & $0.4 \pm 1.1 \mathrm{a}^{*}$ & $0.9 \pm 1.5 \mathrm{a}^{*}$ & \\
\hline After $4 \mathrm{~h}$ of incubation & $0.0 \pm 0.0 \mathrm{a}^{*}$ & $0.4 \pm 1.1 \mathrm{a}^{*}$ & \\
\hline
\end{tabular}

Mean \pm standard deviation.

$\mathrm{a}, \mathrm{b}$ - differences between means in the row with different letters are significant.

A, B - differences between means in the column with different letters are significant.

* Differences between means obtained immediately after dilution and after storage for $96 \mathrm{~h}$ are significant. 
Table 2 - Reproductive parameters of boars kept in pens with or without coffee husk as a floor covering for 60 days $(\mathrm{n}=8)$

\begin{tabular}{lccc}
\hline Variable & $\begin{array}{c}\text { Coffee } \\
\text { group }\end{array}$ & $\begin{array}{c}\text { Control } \\
\text { group }\end{array}$ & P-value \\
\hline Inseminated sows (n) & 84 & 68 & - \\
Average sow parity (n) & $4.1 \pm 2.2$ & $5.5 \pm 2.2$ & - \\
Return to estrus (\%) & $3.6 \mathrm{a}$ & $1.5 \mathrm{a}$ & 0.44 \\
Total newborn piglets per parturition & $15.6 \pm 3.7 \mathrm{a}$ & $16.4 \pm 3.3 \mathrm{a}$ & 0.20 \\
\hline
\end{tabular}

Mean \pm standard deviation.

$\mathrm{a}, \mathrm{b}$ - differences between means in the row with different letters are significant. NS - not significant.

$* \mathrm{P}<0.05 ; * * \mathrm{P}<0.01$.

phosphodiesterases within the cell (Louglin and Agarwal, 1992; Chauhan et al., 1998) and increase the level of intracellular calcium in viable spermatozoa (Colás et al., 2010), elevating the concentration of intracellular cAMP. This elevation has a positive effect on glycolysis (Hicks et al., 1972) and motility enhancement and accelerates maturation and sperm capacitation (Morisawa et al., 1983; Tash and Means, 1983). Nevertheless, none of these effects appears to be present in our experiment, even in the insemination doses stored for longer than $72 \mathrm{~h}$ when the effects of caffeine might be more apparent. Additionally, our results were obtained after a time lapse of 60 days. This is the minimum time needed for the generation and subsequent arrival in the ejaculate of an entire mature wave of sperm (Courot et al., 1970). Thus, our results strongly suggest that coffee husk does not significantly influence boar sperm formation and maturation.

The lack of clear effects linked to the presence of caffeine in semen can be explained by the substrate concentrations obtained from seminal plasma. Our results indicate that seminal plasma caffeine levels are in the $\mu \mathrm{M}$ range. In this respect, Coscione et al. (2001) observed that concentrations of caffeine ranging from 2.5 to $7.5 \mathrm{mM}$ were insufficient to influence the strength and motility of sperm. In fact, Niwa and Ohgada (1988) found that caffeine is only capable of increasing sperm motility, especially in lowerquality ejaculates at concentrations of $10 \mathrm{mM}$. In a similar way, Yeste et al. (2008) found no differences regarding the preservation of semen cooled for $48 \mathrm{~h}$ when $8.0 \mathrm{mM}$ caffeine were added to the semen; however, differences were observed after $72 \mathrm{~h}$ of storage. In any case, the reported effects of caffeine on sperm function are induced at concentrations approaching $10 \mathrm{mM}$. This concentration is much greater than the approximate $100 \mu \mathrm{M}$ obtained in our study. Therefore, a logical supposition would be that the caffeine concentrations reached in the seminal plasma of boars kept in a coffee husk-bed system are not enough to affect the overall semen quality of the animals.
Although chlorogenic acids are present in the coffee husk, we were not able to detect these compounds in the seminal plasma of animals kept in a coffee husk-bed system. This is important, since chlorogenic acids have antioxidant proprieties that are capable of neutralizing free radicals formed within cells due to their redox properties and antiperoxidative membrane (Lekse et al., 2001; Basile et al., 2005; Ghiuru et al., 2010). These characteristics could assist in reducing the oxidative stress in swine sperm, especially when the sperm is stored at $15^{\circ} \mathrm{C}$. Furthermore, ROS at physiological concentrations induce early sperm capacitation, the acrosome reaction, and tyrosine phosphorylation in different species, including swine (Awda et al., 2009), reducing the quality of insemination doses (O'Flaherty et al., 1997). In this way, the presence of chlorogenic acids could act to improve the resistance of boar sperm to ROS; further investigations regarding the possibility of adding chlorogenic acids to coffee husk beds in order to improve the overall quality of boar semen could be assessed. In the present study, although the sperm motility after dilution did not differ significantly between the experimental groups, the data variation observed in the coffee group after $4 \mathrm{~h}$ of incubation (standard deviation = $12.4 \%$ ) was numerically smaller than the change observed in control group (standard deviation $=27.6 \%$ ), suggesting greater stability in the semen quality in the group of animals that were kept in the coffee husk.

The absence of significant differences in the quality of semen would explain the similar results obtained for the rate of return to estrus and the litter size of females inseminated with semen from animals that were kept in stalls that did or did not contain coffee husk as floor covering. Thus, our results clearly indicate that the in vivo fertilizing ability of boars kept under coffee husk-bed conditions remains intact when compared with animals kept on standard beds. This is a very important assertion when considering the possibility of utilizing coffee husk as feasible bedding on farms located in geographical areas in which coffee farmlands are abundant. The utilization of coffee husk in these areas would have an important economic impact on pig production through a significant reduction in economic costs. In this way, the introduction of coffee husk beds could aid in achieving a significant improvement in the economic results of pig farming in areas in which production is penalized by high production costs.

\section{Conclusions}

The use of coffee husks as floor covering worsens the quality of fresh semen and that of insemination doses stored 
for $96 \mathrm{~h}$ but not the quality of semen immediately diluted; therefore, coffee husks may be used only on farms that use semen immediately processed after collection without affecting the reproductive parameters of breeding stock. Caffeine can be measured in the semen, but chlorogenic acids with antioxidant proprieties cannot be detected.

\section{Acknowledgments}

The authors thank CAPES (PNPD Institucional 2457/ 2011 and Programa Pesquisador Visitante Especial - PVE's 88881.030399/2013-01), FAPEMIG (PPM-00359-14), and Minitub do Brasil for the financial support and Fazenda São Paulo and the Department of Veterinary Medicine of Federal University of Lavras (UFLA) for the facilities used in conducting this study.

\section{References}

Awda, B. J.; Mackenzie-Bell, M. and Buhr, M. M. 2009. Reactive oxygen species and boar sperm function. Biology of Reproduction 81:553-561.

Azevedo, A. B. A.; Mazzafera, P.; Mohamed, R. S.; Melo, S. A. B. V. and Kieckbusch, T.G. 2008. Extraction of caffeine, chlorogenic acids and lipids from green coffee beans using supercritical carbon dioxide and co-solvents. Brazilian Journal of Chemical Engineering 25:543-552.

Ball, B. A.; Medina, V.; Gravance, C. G. and Baumbe, J. 2001. Effect of antioxidants on preservation of motility, viability and acrosomal integrity of equine spermatozoa during storage at $5{ }^{\circ} \mathrm{C}$. Theriogenology 56:577-589.

Bamba, K. 1988 Evaluation of acrosomal integrity of boar spermatozoa by bright field microscopy using an eosin-nigrosin stain. Theriogenology 29:1245-1251.

Basile, A.; Ferrara, L.; Pezzo, M. D.; Mele, G.; Sorbo, S.; Bassi, P. and Montesano, D. 2005. Antibacterial and antioxidant activities of ethanol extract from Paullinia cupana Mart. Journal of Ethnopharmacology 102:32-36.

Blom, E. 1950. A one-minute live-dead sperm stain by means of eosin-nigrosin. Fertility and Sterility 1:176 -177 .

Brand, D.; Pandey, A.; Rodríguez-León, J. A.; Roussos, S.; Brand, I. and Soccol, C. R. 2001. Packed bed column fermenter and kinetic modeling for upgrading the nutritional quality of coffee husk in solid-state fermentation. Biotechnology Progress 17:1065-1070.

Breininger, E.; Beorlegui, N. B.; O'Flaherty, C. M. and Beconi, M. T. 2005. Alpha-tocopherol improves biochemical and dynamic parameters in cryopreserved boar semen. Theriogenology 63:2126-2135.

Chatterjee, S. and Gagnon, C. 2001. Production of reactive oxygen species by spermatozoa undergoing cooling, freezing, and thawing. Molecular Reproduction and Development 59:451-458.

Chauhan, M. S.; Singla, S. K.; Palta, P.; Manik, R. S. and Madan, M. L. 1998. Influence of theophylline on cleavage rate and embryonic development following in vitro fertilization of buffalo oocytes. The Indian Journal of Animal Sciences 68:920-922.

Colás, C.; Cebrián-Pérez, J. A. and Muiño-Blanco, T. 2010. Caffeine induces ram sperm hyperactivation independnt of cAMPdependent protein kinase. International Journal of Andrology 33:187-e197.
Coscione, A. C.; Reichenbach, H. D. and Schwartz, J. 2001. Sperm function and production of bovine embryos in vitro after swimup with different calcium and caffeine concentration. Animal Reproduction Science 76:59-67.

Courot, M.; Hochereau-Reviers, M. T. and Ortavant, R. 1970. Spermatogenesis. p.339-431. In: The testis. Johson, A. D.; Gomes, W. R. and Vandemark, N. L., eds. Academic Press, New York.

Ghiuru, F. V.; Ladosi, I.; Roman, I.; Hettig, A.; Zahan, M. and Miclea, V. 2010. Antioxidant medium for mangalita boar semen cryopreservation. Bulletin of University of Agricultural Sciences and Veterinary Medicine Cluj-Napoca. Animal Science and Biotechnologies 67:445-451.

Gollenberg, A. L.; Liu, F.; Brazil, C.; Drobnis, E. Z. and Guzick, D. 2010. Semen quality in fertile men in relation to psychosocial stress. Fertility and Sterility 93:1104-1111.

Hicks, J. J.; Pedron, N. and Rosado, A. 1972. Modifications of human spermatozoa glycolisis by cyclic adenosine monophosphate (cAMP), estrogens, and follicular fluid. Fertility and Sterility 23:886-893.

Johnson, L. A.; Weitze, K. F.; Fiser, P. and Maxwell, W. M. C. 2000. Erratum to "Storage of boar semen". Animal Reproduction Science 62:143-172 (Animal Reproduction Science 64:133-134).

Lekse, J. M.; Xia, L.; Stark, J.; Morrow, J. D. and May, J. M. 2001. Plant catechols prevent lipid peroxidation in human plasma and erythrocytes. Molecular and Cellular Biochemistry 226:89-95.

Louglin, K. R. A. and Agarwal, A. 1992. The use of theophylline to enhance sperm function. Archives of Andrology 28:99-103.

Lovedahl, P.; Damgaard, L. H.; Nielsem, B. L.; Thodgberg, K.; Su, G. and Rydhmer, L. 2005. Aggressive behavior of sows at mixing and maternal behavior are heritable and genetically correlate trits. Livestock Production Science 93:73-85.

Mendez, M. F. B.; Zangeronimo, M. G.; Rocha, L. G. P.; Faria, B. G.; Pereira, B. A.; Fernandes, C. D.; Chaves, B. R.; Murgas, L. D. S. and Sousa, R. V. 2013. Effect of the addition of IGF-I and vitamin E to stored boar semen. Animal 7:793-798.

Morisawa, M.; Suzuki, K.; Shimizu, H.; Morisawa, S. and Yasuda, K. 1983. Effects of osmolality and potassium on motility of spermatozoa from freshwater syprinid fishes. Journal of Experimental Biology 107:95-103.

Niwa, K. and Ohgada, O. 1988. Synergistic effect of caffeine and heparina on in vitro fertilization of cattle oocytes matured in culture. Theriogenology 30:733-774.

O'Flaherty, C.; Beconi, M. and Beorlegui, N. 1997. Effect of natural antioxidants, superoxide dismutase and hydrogen peroxide on capacitation of frozen-thawed bull spermatozoa. Andrologia 29:269-275.

Pandey, A.; Soccol, C. R.; Nigam, P.; Brand, D.; Mohan, R. and Roussos, S. 2000. Biotechnological potential of coffee pulp and coffee husk for bioprocesses. Biochemical Engineering Journal 6:153-162.

Pérez-Llano, B.; Lorenzo, J. L.; Yenes, P.; Trejo, A. and García-Casado, P. 2001. A short hypoosmotic swelling test for the prediction of boar sperm fertility. Theriogenology 56:387-398.

Pope, C. E.; Zhang, Y. Z. and Dresser, B. L. 1991. A simple staining method for evaluating acrosomal status of cat spermatozoa. Journal of Zoo and Wildlife Medicine 22:87-95.

Sanchez-González, I.; Jiménez-Escrig, A. and Jiménez-Escrig, A. 2005. In vitro antioxidant activity of coffees brewed using different procedures (Italian, espresso and filter). Food Chemistry 90:133-139.

Tash, J. S. and Means, A. R. 1983. Cyclic adenosine 3', 5' monophosphate, calcium and protein phosphorylation in flagellar motility. Biology of Reproduction 28:75-104.

Yamaguchi, S.; Suzuki, C.; Noguchi, M.; Kasa, S.; Mori, M.; Isozaki, Y.; Ueda, S.; Funahashi, H.; Kikuchi, K.; Nagai, T. and Yoshioka, K. 2013. 
Effects of caffeine on sperm characteristics after thawing and inflammatory response in the uterus after artificial insemination with frozen-thawed boar semen. Theriogenology 79:87-93.

Yeste, M.; Briz, M.; Pinart, E.; Sancho, S.; Garcia-Gil, N.; Badia, E.; Bassols, J.; Pruneda, A.; Bussalleu, E.; Casas, I. and Bonet, S. 2008.
Hyaluronic acid delays boar sperm capacitation after 3 days of storage at $15^{\circ} \mathrm{C}$. Animal Reproduction Science 109:236-250.

Yoshida, L. M. 2005. Extração de solúveis de casca de café torrada. Dissertation (MSc). Universidade Federal de Uberlândia, Uberlândia, MG, Brazil. 